\title{
Andreas Rüther, Region und Identität. Schlesien und das Reich im späten Mittelalter
}

Köln, Weimar, Wien : Böhlau (Neue Forschungen zur schlesischen

Geschichte, 20), 2010, 346 p., 44,90€.

Mathieu Olivier

\section{(2) OpenEdition}

Journals

Édition électronique

URL : http://journals.openedition.org/ifha/8402

DOI : $10.4000 /$ ifha. 8402

ISSN : 2198-8943

Éditeur

IFRA - Institut franco-allemand (sciences historiques et sociales)

Référence électronique

Mathieu Olivier, «Andreas Rüther, Region und Identität. Schlesien und das Reich im späten Mittelalter», Revue de l'IFHA [En ligne], Date de recension, mis en ligne le 01 février 2016, consulté le 22 septembre 2020. URL : http://journals.openedition.org/ifha/8402 ; DOI : https://doi.org/10.4000/ifha.8402

Ce document a été généré automatiquement le 22 septembre 2020

(CIFHA 


\title{
Andreas Rüther, Region und Identität. Schlesien und das Reich im späten Mittelalter
}

\author{
Köln, Weimar, Wien : Böhlau (Neue Forschungen zur schlesischen
}

Geschichte, 20), 2010, 346 p., 44,90€.

Mathieu Olivier

La notion de "région historique " connaît un beau succès dans l'historiographie récente de l'Europe du Centre-Est, à la faveur de l'abandon des paradigmes nationalistes. La Silésie constitue à cet égard un objet d'étude fascinant - terre à la fois bien identifiable et politiquement évanescente, culturellement puis confessionnellement diverse et pourtant dotée d'une personnalité propre, associée à des princes dont les racines plongent aux origines du royaume de Pologne mais qui regardent vers Prague, Pest ou plus tard Vienne. Justement célébré par l'auteur du présent ouvrage, le médiéviste polonais B. Zientara avait ouvert la voie dans les années 1970 avec un maître-livre sur l'étonnant XIII siècle silésien, Henri le Barbu et son Temps. A. Rüther s'inscrit de façon explicite dans cet effort visant à refonder l'histoire régionale sur de nouvelles bases méthodologiques et conceptuelles. Issu d'une thèse d'habilitation, le présent ouvrage offre en quelque sorte, plus qu'une somme définitive, un état de la réflexion. L'auteur fait la synthèse de ses propres travaux et plus généralement de l'abondante production allemande et polonaise des dernières décennies. Si l'ouvrage est centré sur la période 1350-1500, A. Rüther ne s'interdit pas quelques échappées belles vers le XVI ${ }^{e}$ et le premier XVII ${ }^{e}$ siècle. Évitant la narration classique comme la dispersion monographique - autant de chapitres que de duchés silésiens etc. -, il structure son essai de relecture de l'histoire tardo-médiévale de la province autour de quelques paramètres fondamentaux, marqués au coin des sciences sociales: "Champs» (Felder), «Relations» (Verbindungen), «Tropismes» (Ausrichtungen), « Représentations » (Vorstellungen).

Le résultat surprend, intrigue, agace même parfois. En définitive, l'auteur de ces lignes peine à savoir où $\mathrm{A}$. Rüther veut au fond le conduire. Prolégomènes à la Landesgeschichte 
qui vient ? Énorme bibliographie commentée ? Essai, fort loin des sources (en dépit de la séduisante liste des sources manuscrites donnée aux p. 245-246), sur les notions mêmes d'espace et de territoire médiévaux, exemple régional à l'appui ? Assurément, l'histoire régionale est ici écrite, ou en tout cas présentée d'une autre façon, à la faveur d'un plan savant et assez abstrait. Mais pour quel profit heuristique ? Quel est au fond le Grand dessin [sic, en français dans le texte, p. 122] d'A. Rüther? Trop souvent, les titres ronflants (p. 203: "L'espace comme volonté et représentation»; p. 212: « Bewußtseinsregion gegen Regionsbewußtsein ») accouchent d'une succession de menus paragraphes énonçant assez platement des éléments bien connus. Circonstance aggravante: A. Rüther affectionne un style où la propension à l'ellipse le dispute à la sophistication jargonneuse ; on ne peut s'empêcher de penser que bien des choses dans ce livre pourraient être dites beaucoup plus simplement, concrètement, et modestement (p. 101: "Städtische Lebenskreise werden im Hinblick auf regionale Daseinsweisen gesichtet. Dabei ist weniger die Inventarisierung von Stratifikationen oder alläglichen Frömmigkeitsformen als vielmehr eine Beschreibung der Akteure und ihrer Praktiken beabsichtigt. Zwischen der Abzählung von Archivfunden und der Erzählung von Erfahrungswelten dürften heuristisch weite Wege zu beschreiten sein. »). Aussi subtil qu'il soit ou paraisse, le plan adopté fait la part belle aux pures et simples répétitions - sur le rôle exceptionnel de l'épouse de Charles IV Anna de Schweidnitz, sur la Diète de Breslau en 1420, par exemple. Déplorons enfin la quasi-absence de cartes dans un ouvrage qui met la notion d'espace au cœur du propos (une seule petite carte, assez rudimentaire, p.239). On l'aura compris: l'auteur de ces lignes avoue sans ambages que le livre d'A. Rüther constitue pour lui un objet historiographique non identifié. Une lecture évidemment incontournable pour qui s'intéresse à la Silésie à la charnière du Moyen Âge et des Temps modernes, ne serait-ce que pour l'impressionnante bibliographique brassée par A. Rüther (près de 80 pages) - mais un exercice que l'on hésitera à qualifier de réussi.

Vous trouverez la table des matières ici : http://d-nb.info/1002587506/04.

INDEX

Index chronologique : Moyen Âge, Époque moderne

Thèmes : Histoire des villes et des régions, Histoire de la culture

\section{AUTEUR}

\section{MATHIEU OLIVIER}

Lycée Dumont d'Urville, Toulon 